\title{
Ongoing health care expenditure in survivors of sepsis in the intensive care unit
}

\author{
M Koster-Brouwer ${ }^{1,2^{*}}, K$ van de Groep ${ }^{1,2}$, P Klein Klouwenberg ${ }^{3}$, W Pasma ${ }^{1}, T$ van der Poll ${ }^{4,5}$, M Bonten ${ }^{2,3}$, \\ O Cremer ${ }^{1}$
}

From ESICM LIVES 2015

Berlin, Germany. 3-7 October 2015

\section{Introduction}

Direct costs associated with an intensive care unit (ICU) admission for sepsis are approximately $€ 30,000$ [1]. However, total cost for society is likely to be much higher, because survivors of sepsis may suffer from long-term sequelae that generate ongoing need for health care resources [2].

\section{Objectives}

To estimate the difference in annual health care expenditure before and after an ICU admission for sepsis.

\section{Methods}

Data were derived from a prospective cohort study in two tertiary ICUs in the Netherlands in 2011 and 2012. Patients were included if they had survived one year following a sepsis episode in the ICU. Health care consumption and reimbursed costs were derived from a database of a Dutch health insurance company. The medical ethics committee of the UMC Utrecht approved the study and waived the need for informed consent (IRB-number 14-095).

\section{Results}

Of the 396 eligible patients, for 21 (5.3\%) there was no information on costs available in the study period, leaving 375 subjects for analysis. An overview of reimbursed costs is given in table 1 . For each stage of sepsis severity, total costs were significantly higher in the year following a sepsis admission compared to the year before $(\mathrm{p}<0.001$ for all stages, figure 1). This overall increase in costs was due to the increased use of long-term (home) care ( $\mathrm{p}<0.001$ for all stages), and consultations of the general

${ }^{1}$ University Medical Center Utrecht, Intensive Care Center, Utrecht, Netherlands

Full list of author information is available at the end of the article

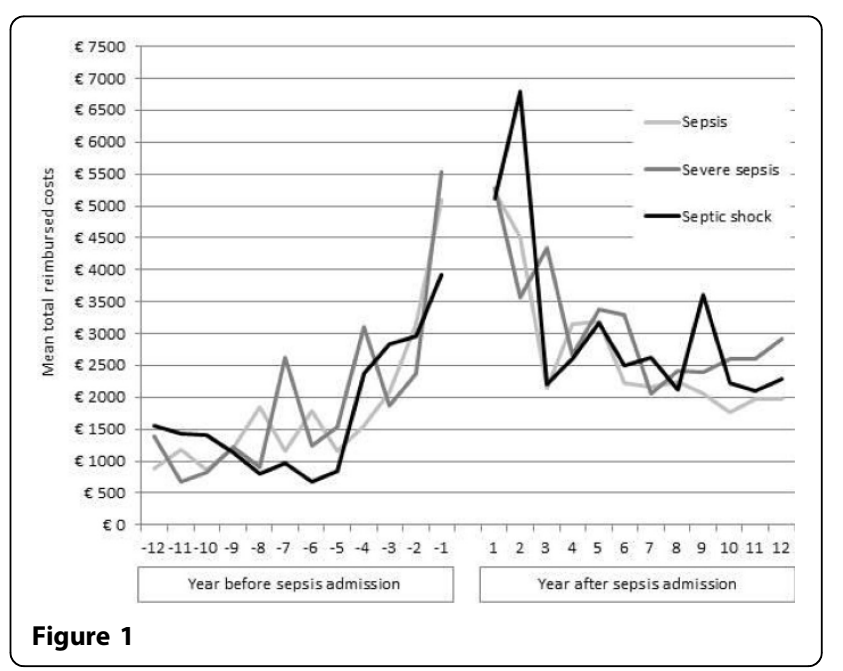

practitioner, paramedic, or mental health professional ( $\mathrm{p}<$ 0.001 for sepsis, $\mathrm{p}=0.008$ for severe sepsis, and $\mathrm{p}<0.001$ for septic shock). In the year after the sepsis episode more patients $(46 \%)$ resided in a long-term care facility or received home care than before the event (10\%). Likewise, the proportion of patients receiving paramedical and mental health care increased from respectively $26 \%$ to $34 \%$ and from $3 \%$ to $9 \%$. Hospital costs following the sepsis episode were significantly higher for patients who had septic shock during their ICU stay ( $\mathrm{p}=0.038)$, but not for patients who had sepsis $(p=0.436)$ or severe sepsis $(p=0.292)$. The opposite was seen for drug use, with a significant increase in costs for patients who had sepsis $(\mathrm{p}=0.002)$ or severe sepsis $(\mathrm{p}=0.021)$, and a non-significant increase for patients who had shock $(\mathrm{p}=0.167)$. We observed no differences in total health care expenditure by disease severity $(\mathrm{p}=0.323)$. 


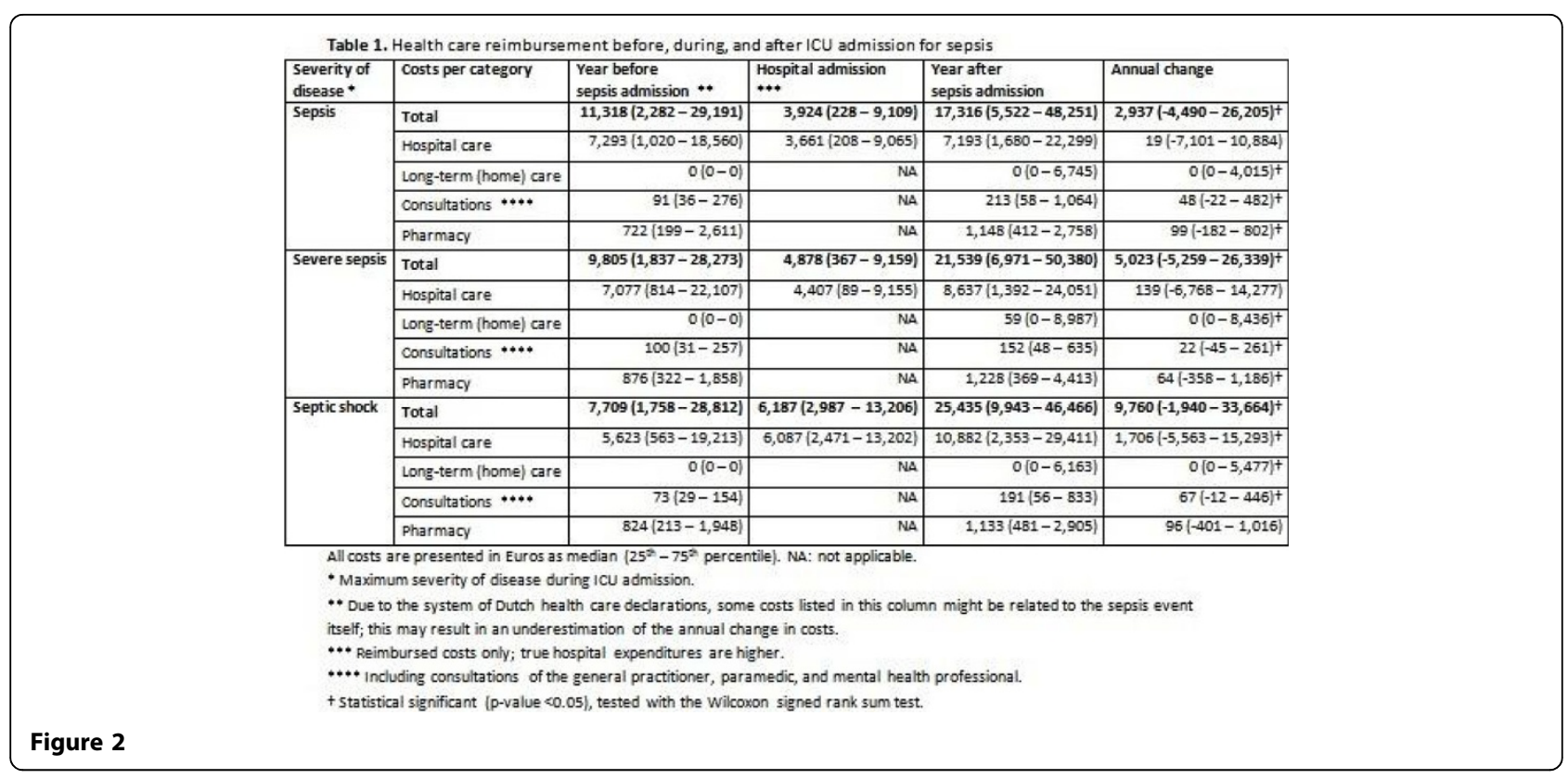

\section{Conclusions}

After successful initial ICU treatment, survivors of sepsis generate substantial health care costs in the year following admission.

\section{Grant Acknowledgment}

This work was supported by the Center for Translational Molecular Medicine, project MARS (grant 04I-201). MB received research funding from the Netherlands Organization of Scientific Research (NWO Vici 918.76.611).

\section{Authors' details}

${ }^{1}$ University Medical Center Utrecht, Intensive Care Center, Utrecht, Netherlands. 'University Medical Center Utrecht, Julius Center for Health Sciences and Primary Care, Utrecht, Netherlands. ${ }^{3}$ University Medical Center Utrecht, Medical Microbiology, Utrecht, Netherlands. ${ }^{4}$ Academic Medical Center, University of Amsterdam, Center of Experimental and Molecular Medicine, Amsterdam, Netherlands. ${ }^{5}$ Academic Medical Center, Infectious Diseases, Amsterdam, Netherlands.

Published: 1 October 2015

\section{References}

1. Moerer $O$, et al: Direct cost of severe sepsis in three German intensive care units based on retrospective electronic patient record analysis of resource use. Intensive Care Med 2002.

2. Yende S, et al: Interplay between sepsis and chronic health. Trends Mol Med 2014.

doi:10.1186/2197-425X-3-S1-A21

Cite this article as: Koster-Brouwer et al:: Ongoing health care expenditure in survivors of sepsis in the intensive care unit. Intensive Care Medicine Experimental 2015 3(Suppl 1):A21.

\section{Submit your manuscript to a SpringerOpen ${ }^{\circ}$ journal and benefit from:}

- Convenient online submission

- Rigorous peer review

- Immediate publication on acceptance

- Open access: articles freely available online

- High visibility within the field

- Retaining the copyright to your article

Submit your next manuscript at $\boldsymbol{s p r i n g e r o p e n . c o m ~}$ 